\title{
IMPLEMENTASI SISTEM JENJANG KARIR DALAM PELAKSANAAN DISCHARGE PLANNING
}

\author{
Wiwin Sulistyawati ${ }^{1}$, Roro Tutik Sri Hariyati ${ }^{2}$, Kuntarti $^{3}$ \\ ${ }^{1}$ Program Studi Ilmu Keperawatan Universitas Kadiri \\ ${ }^{2,3}$ Fakultas IImu Keperawatan Universitas Indonesia
}

\begin{abstract}
ABSTRAK
Discharge planning dapat menurunkan angka rawatan ulang. Penelitian ini bertujuan mengidentifikasi hubungan implementasi sistem jenjang karir dan fungsi manajemen dengan pelaksanaan discharge planning. Desain penelitian deskriptif korelasi dengan pendekatan cross sectional. Sampel penelitian adalah perawat dan dokumen discharge planning masing-masing sebanyak 121. Cara pengambilan data menggunakan simple random sampling dan proportional sampling. Analisis data menggunakan korelasi Spearman. Hasil penelitian menunjukkan ada hubungan implementasi sistem jenjang karir $(p=0,001)$, penilaian kompetensi $(p=0,001)$, kewenangan klinik $(p=0,001)$, pengembangan profesional berkelanjutan $(p=0,001)$, dan fungsi manajemen $(0,001)$ dengan pelaksanaan discharge planning. Hasil penelitian ini merekomendasikan perlunya pelatihan discharge planning bagi perawat untuk meningkatkan kompetensi perawat dalam melaksanakan discharge planning.
\end{abstract}

Kata kunci: sistem jenjang karir, discharge planning, perawat, kompetensi.

\begin{abstract}
Discharge planning can reduce patient readmission. This study aimed to identify relationship of implementation nursing career ladder system and management function to the implementation of discharge planning. Design research was descriptive correlation with cross sectional approach. Data were collected through primary data as much as 121 nurses and also secondary data from patient medical records related to discharge planning documentation. The sampling technique was simple random sampling and proportional sampling. Data were analyzed by spearman correlation. The result showed a significant correlation between implementation of career ladder system $(p=0,001)$, competency assessment $(p=0,001)$, clinical privileges $(p=0,001)$, continuing professional development $(p=0,001)$ and management function $(p=0,001)$ and the implementation of discharge planning. It is recommended to the need for discharge planning training for nurse to improve the competency of nurses in implementing discharge planning.
\end{abstract}

Key words: career ladder system, discharge planning, nurses, competency.

Jurnal Ilmu Keperawatan, Vol:4, No.1,Mei 2016; Korespondensi : Wiwin Sulistyawati. Alamat: Program Studi Ilmu Keperawatan Universitas Kadirijalan Selomangleng no 1 kota kediriEmail: tya_nersunair@yahoo.com 


\section{PENDAHULUAN}

Discharge planning yang belum optimal menimbulkan dampak bagi pasien. Dampak tersebut adalah meningkatnya angka rawatan ulang dan pada akhirnya pasien akan menanggung pembiayaan untuk biaya rawat inap di rumah sakit (Perry \& Potter, 2008). Kondisi kekambuhan pasien ini tentunya sangat merugikan pasien dan keluarga dan juga Rumah Sakit (RS). RS yang mengalami kondisi ini lambat laun akan ditinggalkan oleh pelanggan (Hariyati, 2014).

Beberapa penelitian dilakukan untuk meneliti dampak pelaksanaan discharge planning yang kurang optimal. Penelitian yang dilakukan oleh Moore, Ligget dan Pierson (2003) menunjukkan 49\% pasien kembali ke klinik setelah pulang dari RS karena mempunyai masalah dengan kesehatan. Data di Indonesia, pada tahun 2010 di tiga RS di Kota Bukittinggi didapatkan bahwa terdapat $10 \%$ pasien Penyakit Jantung Koroner (PJK) mengalami rawatan ulang. Diperkirakan bahwa salah satu penyebab terjadinya rawatan ulang yaitu kemungkinan ketidaksiapan pasien pulang ke rumah dengan rata-rata rentang pasien yang mengalami rawatan ulang dari rawatan sebelumnya tiga sampai enam bulan (Wahyuni, Nurachmah \& Gayatri, 2012).

Pelaksanaan discharge planning yang tepat bermanfaat bagi pasien. Cherlin, Curry, Thompson, Greysen, Spatz, Krumholz, dan
Bradley (2012), menyatakan discharge planningmengurangi resiko kematian pasien Infark Miocardial Acute (IMA) pasca 30 hari keluar dari RS. Penelitian senada juga diungkapkan oleh Fox, Persaud, Maimets, Broks, O’Briens, dan Trengguno (2013), yang menyatakan terdapat hubungan yang bermakna antara discharge planning dengan penurunan angka rawatan ulang dalam satu sampai 12 bulan indeks pemulangan pasien.

Keberhasilan discharge planning dipengaruhi oleh beberapa faktor. Faktor-faktor tersebut antara lain; keterlibatan dan partisipasi, komunikasi, waktu, perjanjian dan konsensus serta personil discharge planning (Poglitsch, Emery \& Darragh, 2011). Coleman dan Chalmers (2006) menjelaskan bahwa tipe rumah sakit (pendidikan atau umum), kompleksitas pasien, dan kompetensi perawat ikut mempengaruhi keberhasilan pelaksanaan discharge planning. Hariyati, Afifah, dan Handiyani (2010), menyatakan bahwa ada peningkatan pengetahuan perawat setelah dikenalkan model pelaksanaan discharge planning dan adanya peningkatan pelaksanaan yang bermakna setelah dikenalkan model discharge planning.

Salah satu cara yang dilakukan RS untuk meningkatkan kompetensi perawat adalah dengan sistem jenjang karir. Sistem jenjang karir perawat memberikan pengakuan dan 
penghargaan atas kontribusi perawat dalam memberikan pelayanan keperawatan yang berkualitas dan berdasarkan pada evidence based practice, sehingga memberikan dampak positif terhadap hasil yang dicapai pasien (Burket, 2010).Implementasi sistem jenjang karir terdiri dari pemetaan, penilaian kompetensi, credentialing, kewenangan klinik, dan Pengembangan Profesional Berkelanjutan (PPB) (Depkes, 2013).

Implementasi sistem jenjang karir bermanfaat untuk meningkatkan kinerja perawat, mutu pelayanan keperawatan dan kepuasan perawat.Penelitian Nelson dan Cook (2008), tentang evaluasi program jenjang karir di rawat jalan menunjukkan bahwa ada peningkatan kualitas pelayanan yang diberikan oleh perawat yang mempunyai level karir. Sitinjak (2008), menyatakan bahwa berdasarkan hasil wawancara dengan Direktur RS "Imanuel" bandung yang sudah menerapkan sistem jenjang karir, bahwa implementasi sistem jenjang karir telah berpengaruh terhadap kepuasan kerja perawat dan berpengaruh pula terhadap peningkatan mutu pelayanan keperawatan. Discharge planning merupakan salah satu indikator mutu pelayanan keperawatan. Beberapa RS belum melakukan penilaian pelaksanaan discharge planning di RSdengan instrumen yang objektif, dan terstruktur mulai dari pengkajian sampai dengan evaluasi dan belum adanya penilaian terkait implementasi sistem jenjang karir berdasarkan persepsi perawat. RSUD Cengkareng belum pernah dilakukan penelitian ini untuk mengetahui pelaksanaan discharge planning dan persepsi perawat terkait implementasi sistem jenjang karir perawat klinik di ruang rawat inap.

\section{METODE}

Desain penelitian ini adalah deskriptif korelasi dengan rancangan penelitian cross sectionaluntuk mengidentifikasi hubungan implementasi sistem jenjang karir perawat klinik dengan pelaksanaan discharge planning. Sampel dalam penelitian ini adalah perawat pelaksana di ruang rawat inap RS tipe B di Jakarta Barat. Sampel diambil dengan teknik proportional sampling untuk mengambil perawat di tiap-tiap ruangan mewakili jenjang karir perawat Junior Nurse (JN), Senior Nurse (SN), dan Shift Charge Nurse (SCN).Simple random sampling untuk memilih responden dari masing- masing ruangan untuk tiap jenjang karir dengan melakukan undian nomor urut perawat sesuai dalam daftar perawat di ruang tersebut setelah dikelompokkan sesuai jenjang karirnya.Kriteria inklusi adalah perawat di ruang rawat inap yang mempunyai jenjang karir dan tidak sedang tugas belajar.Jumlah sampel sebanyak 121 orang.

Data dikumpulkan menggunakan kuesioner implementasi sistem jenjang karir untuk 
perawat dan panduan observasi discharge planning untuk dokumen discharge planning. Kuesioner implementasi sistem jenjang karir dibuat peneliti dengan berpedoman pada Depkes (2013).Pedoman observasi dokumen mengacu pada pedoman observasi pelaksanaan discharge planning National Council of Social Services (NCSS) dan Rofi'i (2011).

Hasil uji validitas menggunakan Pearson product moment didapatkan nilai validitas antara 0,372-0,805. Hasil uji reliabilitas instrumen dengan alpha cronbach didapatkan $r$ $=0,912$. Penelitian ini mempertimbangkan prinsip dasar etik penelitian keperawatan yaitu menghormati harkat dan martabat manusia, menghormati privasi dan kerahasiaan subjek, menghormati keadilan dan inklusivitas, serta memperhitungkan manfaat dan kerugian yang ditimbulkan.Penelitian ini sudah lolos uji etik dari Komite Etik Penelitian Fakultas IImu Keperawatan Universitas Indonesia nomor 0323/UN2F2.D/HKP.02.04/2015.

\section{HASIL}

\section{Karakteristik Responden}

Sebagian besar jenis kelamin responden adalah perempuan (90,1\%), rerata umur responden 27 tahun dengan umur termuda 21 tahun dan tertua 45 tahun, dan rerata lama kerja 5 tahun dengan lama kerja tersingkat 2 tahun dan terlama 13 tahun. Tingkat pendidikan dan jenjang karir dijelaskan secara rinci pada tabel berikut.

Tabel 1 Karakteristik perawat di RSUD Cengkareng Juni 2015 ( $n=121)$

\begin{tabular}{lcc}
\hline \multicolumn{1}{c}{ Variabel } & $\begin{array}{c}\text { Frekuen } \\
\text { si n=121 }\end{array}$ & $\%$ \\
\hline Pendidikan n (\%) & & \\
DIII Keperawatan & 109 & 90,9 \\
S1 Keperawatan/ & 12 & 9,1 \\
Ners & & \\
Level Karir & & \\
Junior Nurse (JN) 1 & 41 & 33,9 \\
Junior Nurse (JN) 2 & 4 & 33,9 \\
Senior Nurse (SN) 1 & 20 & 16,5 \\
Senior Nurse (SN) 2 & 9 & 7,4 \\
Shift Charge Nurse & 10 & 8,3 \\
(SCN) & & \\
\hline
\end{tabular}

Tabel 2. Hubungan implementasi sistem jenjang karir dengan pelaksanaan discharge planning di RSUD Cengkareng Juni 2015 ( $n=121)$.

\begin{tabular}{lcc}
\hline \multirow{2}{*}{ Variabel } & \multicolumn{2}{c}{$\begin{array}{c}\text { Pelaksanaan Discharge } \\
\text { Planning }\end{array}$} \\
\cline { 2 - 3 } & $\mathrm{R}$ & Nilai $\mathrm{p}$ \\
\hline $\begin{array}{l}\text { Implementasi sistem } \\
\text { jenjang karir }\end{array}$ & 0,360 & $0,001^{*}$ \\
a. Pemetaan Perawat & 0,150 & 0,101 \\
b. Penilaian & 0,337 & $0,001^{*}$ \\
$\quad$ Kompetensi & & \\
c. Credentialing & 0,142 & 0,121 \\
d. Pemberian & 0,292 & $0,001^{*}$ \\
e. Kewenangan Klinik & & \\
\hline
\end{tabular}

* Bermakna pada $\alpha 0,05$.

Hasil analisis menunjukkan bahwa ada hubungan implementasi sistem jenjang karir dengan pelaksanaan discharge planning $(p=0,001)$ dengan tingkat hubungan sedang dan berpola positif $(r=360)$. Hasil penelitian dapat disimpulkan ada hubungan yang signifikan penilaian kompetensi, pemberian kewenangan klinik dan PPB dengan pelaksanaan discharge planning, tetapi tidak terdapat hubungan 
pemetaan perawat dan credentialing dengan pelaksanaan discharge planning di ruang rawat inap RS.

\section{PEMBAHASAN}

Sebagian besar perawat yang menjadi responden di tempat penelitian adalah perempuan. Banyaknya perawat dalam penelitian ini tidak mempengaruhi hasil penelitian karena jenis kelamin tidak berpengaruh pada kinerja, dalam penelitian ini pelaksanaan discharge planning. Robbins dan Judge (2013), menyatakan bahwa tidak ada perbedaan antara laki-laki dan perempuan dalam kinerja, kemampuan memecahkan masalah, keterampilan analisis, motivasi dan dorongan kompetitif.

Mayoritas perawat yang menjadi responden berpendidikan D3 Keperawatan. Faktor pendidikan penting dalam implementasi sistem jenjang karir karena kualifikasi jenjang karir yang diakui oleh Depkes (2006) adalah perawat dengan minimal pendidikan keperawatan D3 Keperawatan. Hasil penelitian ini menunjukkan tidak ada hubungan yang bermakna antara tingkat pendidikan dengan discharge planning. Hal senada juga disampaikan Hariyati, Afifah dan Handiyani (2010), mengatakan bahwa tidak ada korelasi antara tingkat pendidikan dan persepsi tentang pelaksanaan discharge planning sebelum dan sesudah penjelasan discharge planning yang terstruktur dan terencana.

Lebih dari separuh perawat mempunyai level karir junior nurse. Hasil penelitian ini bisa dijelaskan karena mayoritas perawat mempunyai lama kerja 5 tahun dan berpendidikan D3 Keperawatan.Berdasarkan model jenjang karir Depkes (2006) perawat klinik I (PK I), perawat lulusan D3 Keperawatan dengan pengalaman kerja 2 tahun atau S1 Keperawatan (Ners) 0 tahun pengalaman. Sebagian perawat di tempat penelitian mempunyai level junior nurse atau kalau disejajarkan dengan model jenjang karir Depkes adalah PK 1. Level karir perawat tidak berpengaruh terhadap pelaksanaan discharge planning hal ini senada dengan hasil penelitian sebelumnya yang menyatakan tidak ada hubungan antara level jenjang karir dengan kinerja perawat di IRNA RSUD Banyumas (Suroso, 2011).

Rerata umur perawat di tempat penelitian berada pada umur produktif yaitu 27 tahun.Apabila RS bisa mengelola sumber daya ini dengan baik sesuai dengan potensinya bisa menjadi aset yang potensial bagi RS.Penelitian Robbins dan Judge (2013), yang meyatakan bahwa produktivitas seseorang dipengaruhi oleh umur.Rerata lama kerja perawat di RSUD Cengkareng 5 tahun.Hasil ini bisa dijelaskan karena RS tersebut baru berumur 13 tahun dengan status kepegawaian mayoritas pegawai RS bukan PNS. Lama kerja bisa mempengaruhi 
produktivitas kerja perawat, sesuai dengan Siagian (2009) yang menyatakan lama kerja mempengaruhi pengalaman dan produktivitas, semakin lama kerja semakin banyak pengalaman dan produktivitas meningkat.

Implementasi sistem jenjang karir mempunyai hubungan yang bermakna dengan pelaksanaan discharge planning. Implementasi sistem jenjang karir bermanfaat untuk meningkatkan kepuasan kerja, kualitas perawatan dan menambah kompetensi baru. Jennings (2009), mengatakan bahwa jenjang karir bermanfaat untuk memperbaiki retensi dan rekruitmen, peningkatan kepuasan kerja, otonomi, dan kualitas perawatan pasien. Mutu pelayanan keperawatan terdiri dari enam indikator, discharge planning merupakan salah satu dari indikator mutu keperawatan. Implementasi penjenjangan karir terdiri dari beberapa tahapan antara lain pemetaan untuk menentukan level perawat, penilaian kompetensi, credentialing, kewenangan klinik, dan PPB (Depkes, 2013).

Implementasi pemetaan tidak mempunyai hubungan yang bermakna dengan pelaksanaan discharge planning. Hal ini dikarenakan pemetaan yang dilakukan masih sebatas dokumen, perawat dilakukan pemetaan berdasarkan lama kerja, tingkat pendidikan dan pelatihan, perawat baru tidak dilakukan penilaian kompetensi untuk menentukan jenjang karir. Depkes (2013), menyatakan bahwa proses implementasi pemetaan terdiri dari: (1) survei data dasar perawat saat ini mencakup nama, pendidikan keperawatan terakhir, pelatihan, lama bekerja, umur, golongan/ pangkat atau level, (2) melakukan review dan analisis hasil survei data dasar untuk menetapkan level setiap perawat, menyusun rekapitulasi profil perawat berdasarkan penjenjangan karirnya, dan (4) setiap perawat mengikuti penilaian kompetensi.

Hasil penelitian didapatkan ada hubungan antara persepsi perawat terhadap penilaian kompetensi dengan pelaksanaan discharge planning. Peningkatan pelaksanaan discharge planning yang sejalan dengan peningkatan persepsi perawat pelaksana tentang penilaian kompetensi perawat karena dengan adanya implementasi sistem jenjang karir memungkinkan perawat untuk menambah kompetensi baru dan diharuskan mencapai kompetensi tertentu yang ditetapkan agar bisa naik ke jenjang lebih tinggi. Hal ini tentu berdampak pada pelaksanaan discharge planning yang merupakan bagian dari asuhan keperawatan.

Credentialing tidak mempunyai hubungan yang signifikan dengan pelaksanaan discharge planning. Hal ini dikarenakan credentialing masih bersifat administratif, belum melibatkan 
mitra bestari dan belum ada komite keperawatan yang mengatur tentang credentialing. Belum adanya komite keperawatan mengakibatkan proses credentialing belum berjalan dengan baik karena komite keperawatan bertanggung jawab melakukan credentialing bagi seluruh tenaga keperawatan yang akan melakukan pelayanan keperawatan di RS. Komite Keperawatan bertugas untuk melaksanakan fungsi credentialing. Sutoto (2014), credentialing penting untuk menentukan kelayakan pemberian kewenangan klinik kepada perawat, sehingga jika credentialing berjalan baik akan berpengaruh pada kemampuan perawat dalam melakukan tugas yang menjadi kewenangan kliniknya. Pelaksanaan discharge planning merupakan bagian dari pemberian asuhan keperawatan kepada pasien yang merupakan tugas keperawatan yang dilakukan secara mandiri dan berkolaborasi dengan tenaga kesehatan lain. Credentialing bertujuan untuk memastikan staf keperawatan kompeten dan bertanggung jawab untuk memberikan asuhan keperawatan langsung.

Hasil penelitian menunjukkan ada hubungan bermakna antara pemberian kewenangan klinik dengan discharge planning. Peran dan fungsi perawat sebagai educator terlihat dengan pelaksanaan discharge planning. Caroll dan Dowling (2007), menyatakan bahwa perawat sebagai discharge planners bertugas membuat rencana, mengkoordinasikan, memonitor, dan memberikan tindakan dan proses kelanjutan perawatan. Perawat melaksanakan tugasnya dalam memberikan asuhan keperawatan sesuai dengan SKPK yang telah diberikan. Selain itu perawat dituntut untuk mempertahankan, mengembangkan dan meningkatkan kompetensi melalui program PPB.

Hasil penelitian didapatkan ada hubungan yang bermakna antara PPB dengan pelaksanaan discharge planning. PPB sudah dilakukan di tempat penelitian akan tetapi pemetaan PPB masih berdasarkan persepsi Kepala Ruangan, belum berdasarkan kesenjangan kompetensi perawat. PPB berpengaruh kepada ketrampilan dan kualitas pelayanan kepada pasien dalam hal ini pelaksanaan discharge planning.Depkes (2013), yang menyatakan bahwa PPB bagi perawat dilaksanakan dalam rangka mempertahankan dan meningkatkan kompetensi perawat agar tetap berorientasi pada proses dan keselamatan pasien.

\section{KESIMPULAN}

Kesimpulan hasil penelitian ini yaitu; karakterisistik perawat di ruang rawat inap RSUD Cengkareng rerata umur 27 tahun dengan rentang umur 21 sampai dengan 45 tahun. Mayoritas berjenis kelamin perempuan, berpendidikan D3 Keperawatan, dan lebih dari separuh perawat pada jenjang junior nurse atau PK 1, (2) implementasi sistem jenjang karir di 
ruang rawat inap RSUD Cengkareng mempunyai rerata 51 (68,9\%), dengan nilai persepsi terendah 37 dan tertinggi, (3) tidak ada hubungan yang bermakna antara karakteristik perawat pelaksana (jenis kelamin, tingkat pendidikan, jenjang karir, umur, dan lama kerja) dengan pelaksanaandischarge planning, (4) ada hubungan yang bermakna antara implementasi sistem jenjang karir dengan pelaksanaan discharge planning, dan (5) ada hubungan yang bermakna implementasi penilaian kompensi, kewenangan klinik, dan PPB dengan pelaksanaan discharge planning.

\section{SARAN}

\section{DAFTAR PUSTAKA}

Azies., Nurachmah, E., \& Notoatmojo. (2012). Persepsi kepala ruangan dan perawat pelaksana tentang permasalahan manajemen dalam menerapkan pendokumentasian proses keperawatan di RSUPN Dr. Cipto Mangunkusumo Jakarta. Jurnal Keperawatan Indonesia. elSSN:2354-9203.

Burket., Feimlee., Greider., Hippensteel., Rohrer., \& Shay. (2010). Clinical ladder program evolution: Journey from novice to expert to enhancing outcomes. The
Implementasi sistem jenjang karir yang baik diperlukan penilaian kompetensi yang dilengkapi dengan self asessmen oleh perawat, pembentukan komite keperawatan agar credentialing berjalan baik, penerbitan Surat Keputusan Kewenangan Klinik (SKPK), dan adanya pemetaan Pengembangan Profesional Berkelanjutan (PPB) untuk mengatasi kesenjangan kompetensi perawat. Pelaksanaan discharge planning perlu melibatkan tim kesehatan lain secara terintegrasi dan perlu adanya materi discharge planning dalam pelatihan PPB untuk meningkatkan kompetensi perawat dalam melaksanakan discharge planning.

Journal Education in Nursing. Vol 41(8). DOI:10.3928/00220124-20100503-07.

Caroll, A \& Dowling. (2007). Discharge planning: Communication, education, and patient participation. British Journal of Nursing. 16. $15-21$.

Coleman, E \& Chalmers, S. (2006).The care transition intervention: Results of randomized controlled trial. Archives of Internal Medicine. 166. 1822-1828. http://www.archintermed.com/.

Cherlin, E., Curry, L., Thompson, J., Greysen, S., Spatz, E., Krumholz, H., \& Bradley, E. (2012). Features of high quality 
discharge planning for patients following acute myocardial infarction. Journal general internal medicine. 28(3):436-443. Doi:10.1007/s11.606012-2234-y.

Depkes RI. (2013). Petunjuk pelaksanaan jenjang karir perawat di rumah sakit.Jakarta: Direktorat Bina Pelayanan Keperawatan dan Keteknisian Medik Direktorat Jenderal Bina Upaya Kesehatan

Fox, M., Persaud, M., Maimets, I., Broks, D., O'Briens, K., \& Trengguno, D. (2013). Effectiveness of early discharge planning in acutely ill or injured hospitalized older adults: a systematic review and meta analysis. $\quad B M C$ Geriatrics.http://www.biomedcentral.co $\underline{m} / 1471-2318 / 13 / 70$.

Hariyati, R. T. S. (2004). Correlation of stress management with preparing and adaptive response of stroke patient. Nursing Journal Indonesia. Vol 8.

Hariyati, R. T. S., Afifah, E., \& Handiyani, H. (2010). Developing prototype model of discharge planning with $C D$ learning media in Indonesia. Scientifics Research and Essays. Vol 5 (12), pp 1463-1469. ISSN 1992-2248. http://www.academicsjournals.org/SRE.
Jennnings. (2009). Factors contributing to decision to participate or not participate in a clinical ladder program. The journal of nursing administration: Union Kentucky.

Moore., Ligget., \& Pierson. (2003). Medical errors related to discontinuity of care from an patient to an outpatient setting. Journal General Internal Medicine. 18:646-65.

Nelson, J. M., \& Cook, P. F. (2008). Evaluation of a career ladder program in an ambulatory care environment.Nursing Economics. 26(6),393-398. http://search.proquest.com/docview/2

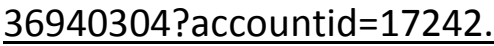

Perry A. G., \& Potter P. A. (2005). Buku ajar fundamental keperawwatan: Konsep, proses, \& praktik. (Volume 1, Edisi 4). (Alih bahasa: Yasmin Asih, et al: Editor edisi bahasa Indonesia Devi Yuliati, Monica Ester). Jakarta: Penerbit Buku Kedokteran EGC.

Poglitsch, L, A., Emery, M., \& Darragh, A. (2011).A qualitative study of determinant of successful discharge for older adult inpatient.Journal of American Physical Therapy Association.(ISSN 1538-6724).

Rofi'i., Hariyati., \& Pujasari. (2012). Perjanjian dan konsensus dalam pelaksanaan perencanaan pulang pada perawat di 
rumah sakit. Jurnal Keperawatan

Indonesia. Volume 15 (3), 207-214.

http://jki.ui.ac.id.

Siagian, S.P. (2006). Teori dan praktek kepemimpinan.Cetakan kelima. Jakarta: PT Rineka Cipta.

Sutoto. (2014). Persiapan bidang pelayanan keperawatan terkait Undang Undang Keperawatan dalam standar akreditasi RS. http://www.pdpersi.co.id./kegiatan/mat

eri_uu382014/akreditasirs2012.pdf

Wahyuni., Nurachmah, E., \& Gayatri. (2012). Kesiapan pulang pasien penyakit jantung koroner melalui penerapan discharge planning. Jurnal Keperawatan Indonesia. Vol 15(3):151-58

http://jki.ui.ac.id/index.php/jki/article/view $\angle 3$. 